\title{
REVIEW
}

\section{Fever management in intensive care patients with infections}

\author{
Paul J Young ${ }^{1 *}$, Manoj Saxena² \\ This article is one of ten reviews selected from the Annual Update in Intensive Care and Emergency Medicine 2014 and co-published as a series \\ in Critical Care. Other articles in the series can be found online at http://ccforum.com/series/annualupdate2014. Further information about the \\ Annual Update in Intensive Care and Emergency Medicine is available from http://www.springer.com/series/8901.
}

\section{Introduction}

'Humanity has but three great enemies:

fever, famine and war; of these by far the greatest, by far the most terrible, is fever' [1].

Fever is one of the cardinal signs of infection and, nearly 120 years after William Osler's statement in his address to the $47^{\text {th }}$ annual meeting of the American Medical Association [1], infectious diseases remain a major cause of morbidity and mortality. Despite this, it is unclear whether fever itself is truly the enemy or whether, in fact, the febrile response represents an important means to help the body fight infection. Furthermore, it is unclear whether the administration of antipyretic medications or physical cooling measures to patients with fever and infection is beneficial or harmful [2], [3]. Here, we review the biology of fever, the significance of the febrile response in animals and humans, and the current evidence-base regarding the utility of treating fever in intensive care patients with infectious diseases.

\section{The biology of fever}

\section{Regulation of normal body temperature}

Thermoregulation is a fundamental homeostatic mechanism that maintains body temperature within a tightly regulated range. The ability to internally regulate body temperature is known as endothermy and is a characteristic of all mammals and birds. The thermoregulatory system consists of an afferent sensory limb, a central processing center, and an efferent response limb. In humans, the central processing center controlling the thermoregulatory set-point is the hypothalamus. Both warm-sensitive and cold-sensitive thermoreceptors are

*Correspondence: paul.young@ccdhb.org.nz

'Intensive Care Unit, Wellington Regional Hospital, Wellington, New Zealand

Full list of author information is available at the end of the article involved in the afferent limb. Stimulation of the coldsensitive receptors activates efferent responses relayed via the hypothalamus that reduce heat loss and increase heat production. These responses include reducing blood flow to the peripheries and increasing heat production by mechanisms including shivering. Conversely, stimulation of warm-sensitive receptors ultimately increases heat loss through peripheral vasodilation and evaporative cooling caused by sweating.

\section{The cellular and molecular basis of the febrile response}

Upward adjustment of the normal hypothalamic thermoregulatory set-point leading to fever is typically part of a cytokine-mediated systemic inflammatory response syndrome that can be triggered by various infectious etiologies including bacterial, viral, and parasitic infections as well as by a range of non-infectious etiologies including severe pancreatitis and major surgery.

In patients with sepsis, the febrile response involves innate immune system activation via Toll-like receptor 4 (TLR-4). This activation leads to production of pyrogenic cytokines including interleukin (IL)-1 $\beta$, IL-6, and tumor necrosis factor (TNF)- $\alpha$. These pyrogenic cytokines act on an area of the brain known as the organum vasculosum of the laminae terminalis (OVLT) leading to the release of prostaglandin $\mathrm{E}_{2}\left(\mathrm{PGE}_{2}\right)$ via activation of the enzyme cyclo-oxygenase-2 (COX-2). $\mathrm{PGE}_{2}$ binds to receptors in the hypothalamus leading to an increase in heat production and a decrease in heat loss until the temperature in the hypothalamus reaches a new, elevated, set-point. Once the new set-point is attained, the hypothalamus maintains homeostasis around this new set-point by the same mechanisms involved in the regulation of normal body temperature. However, in addition, there are a number of important specific negative feedback systems in place that prevent excessive elevation of body temperature. One key system is the glucocorticoid system, which acts via nuclear 
factor-kappa B (NF-kB) and activator protein-1 (AP-1). Both these mediators have anti-inflammatory properties and downregulate the production of pyrogenic cytokines, such as IL-1 $\beta$, IL- 6 , and TNF- $\alpha$. The febrile response is further modulated by specific antipyretic cytokines including IL-1 receptor antagonist (IL-1RA), IL-10, and TNF- $\alpha$ binding protein.

\section{Heat shock proteins and the febrile response}

The negative feedback systems outlined above are not the only mechanisms that exist to protect cells from being damaged by the febrile response. In addition, the heat shock proteins (HSPs) provide intrinsic resistance to thermal damage. Genes encoding the HSPs probably first evolved more than 2.5 billion years ago. They represent an important system providing protection to cells, not only against extremes of temperature, but also against other potentially lethal stresses including toxic chemicals and radiation injury. During heat-stress, transcription and translation of HSPs is upregulated. HSPs can then trigger refolding of heat-damaged proteins preserving them until heat-stress has passed or, if necessary, can transport denatured proteins to organelles for intracellular degradation. As well as providing protection against cellular damage from the thermal stress induced by fever, the HSPs may themselves be important regulators of the febrile response. For example, HSP 70 inhibits pyrogenic cytokine production via NF- $\mathrm{kB}$. HSPs also inhibit programmed cell death, which might otherwise be induced by an invading pathogen.

\section{The physiological consequences of fever}

The febrile response leads to a marked increase in metabolic rate. In humans, generating fever through shivering increases the metabolic rate above basal levels by six-fold [4]. In critically ill patients with fever, cooling reduces oxygen consumption by about $10 \%$ per ${ }^{\circ} \mathrm{C}$ decrease in core temperature and significantly reduces cardiac output and minute ventilation [5]. Any potential benefit of the febrile response needs to be weighed against this substantial metabolic cost.

\section{The immunological consequences of fever}

Temperatures in the physiological febrile range stimulate the maturation of murine dendritic cells. This is potentially important because dendritic cells act as the key antigen presenting cells in the immune system. Human neutrophil cell motility and phagocytosis are enhanced by temperatures in the febrile range, and growth of intracellular bacteria in human macrophages in vitro is reduced by temperatures in the febrile range compared to normal temperatures. Murine macrophages demonstrate a range of enhanced functions at temperatures in the febrile range. These effects include enhanced expression of the Fc receptors that are involved in mediating antibody responses, and enhanced phagocytosis. Temperatures in the physiological febrile range enhance binding of human lymphocytes to the vascular endothelium. This L-selectin-mediated binding is important in facilitating lymphocyte migration to sites of tissue inflammation or infection. In mice, T lymphocytemediated killing of virus-infected cells is increased by temperatures in the febrile range and helper T-cell potentiation of antibody responses is enhanced. In contrast to other cells of the immune system, the cytotoxic activity of natural killer cells is reduced by temperatures in the febrile range compared to normal body temperature. Although their functions are enhanced by temperatures in the physiological febrile range $\left(38-40{ }^{\circ} \mathrm{C}\right)$, neutrophils and macrophages have substantially reduced function at temperatures of $\geq 41^{\circ} \mathrm{C}$.

\section{The effects of fever on the viability of microbial pathogens}

Temperatures in the human physiological febrile range cause direct inhibition of some viral and bacterial organisms such as influenza virus [6], Streptococcus pneumonia [7], [8], and Neisseria meningitides [9] which can all cause life-threatening illnesses. For influenza, the degree of heat sensitivity appears to be a determinant of virulence, such that strains with a shut-off temperature of $\leq 38{ }^{\circ} \mathrm{C}$ cause mild symptoms, whereas strains with a shut-off temperature of $\geq 39{ }^{\circ} \mathrm{C}$ cause severe symptoms [6]. The susceptibility of a pathogen to heat may have significance in terms of its pathogenicity in a particular host. For example, Campylobacter jejuni is not pathogenic in birds (body temperature $42{ }^{\circ} \mathrm{C}$ ) but is pathogenic in humans (body temperature $37^{\circ} \mathrm{C}$ ) and the growth and chemotactic ability of $C$. jejuni in vitro are greater at $37{ }^{\circ} \mathrm{C}$ than at $42^{\circ} \mathrm{C}[10]$.

\section{The significance of fever in animals with infections}

The febrile response to infection is seen in a range of animal species including not only endotherms, such as mammals and birds, but also ectotherms, including reptiles, amphibians, and fish. The febrile response can be blocked by inhibition of COX in a diverse range of species including desert iguanas [11] and bluegill sunfish [12], as well as higher animals like humans. As COX catalyzes the generation of prostaglandins from arachidonic acid, this suggests that the pivotal role of $\mathrm{PGE}_{2}$ in the regulation of the thermostatic set-point may be preserved in these species as well as in higher animals. Such a common biochemical mechanism to regulate fever across such a diverse group of animals raises the possibility that the febrile response may have evolved in a common ancestor. If this is the case, then fever probably emerged as an evolutionary response more than 350 million 
years ago [13]. As the febrile response comes at a significant metabolic cost [4], [5], its persistence across such a broad range of species provides strong circumstantial evidence that the response has some evolutionary advantage. Furthermore, given that the response appears ubiquitous, it logically follows that the components of the immune system would have evolved to function optimally in the physiological febrile range.

In experimental models in mammals, the febrile response appears to offer a survival advantage across a range of viral infections. Newborn mice infected with coxsackie virus, which are allowed to develop a fever have a much lower mortality than mice which are prevented from developing a fever [14]. Similarly, increasing the environmental temperature from $23-26{ }^{\circ} \mathrm{C}$ to $38{ }^{\circ} \mathrm{C}$ increases the core temperature of Herpes simplex-infected mice by about $2{ }^{\circ} \mathrm{C}$ and increases their survival from $0 \%$ to $85 \%$ [15]. A meta-analysis of the effect of antipyretic medications on mortality in animal models of influenza infection demonstrated that antipyretic treatment was associated with an increased mortality risk [OR 1.34 (95 \% CI 1.04-1.73)] [16].

Studies in mammalian models of bacterial infections have generally yielded similar results. In rabbits infected with Pasteurella multocida, the presence of a mild fever of up to $2.25{ }^{\circ} \mathrm{C}$ above normal was correlated with the greatest chance of survival compared to either normothermia or fever of $>2.25{ }^{\circ} \mathrm{C}$ above normal [17]. Although mice are predominantly endothermic, they appear to require external sources of heat to generate a fever. If mice are allowed to position themselves in a cage with a temperature gradient, they increase their ambient temperature preference and elevate their core temperature by $1.1{ }^{\circ} \mathrm{C}$ after a lipopolysaccharide (LPS) challenge [18]. Housing mice at $35.5^{\circ} \mathrm{C}$ rather than $23^{\circ} \mathrm{C}$ increases their core body temperature by about $2.5{ }^{\circ} \mathrm{C}$, alters cytokine expression, and improves survival in Klebsiella pneumoniae peritonitis [19]. In this model, the elevated body temperature seen with increased ambient temperature was associated with a 100,000-fold reduction in the intraperitoneal bacterial load [19]. A recently published systematic review and meta-analysis of the effects of antipyretic medications on mortality in $S$. pneumoniae infection identified four animal studies comparing aspirin to placebo and demonstrated that the administration of aspirin was associated with an increased risk of death [OR 1.97 (95 \%CI 1.22-3.19)] [20].

\section{The significance of fever in humans with infection Fever, hyperthermia, and antipyresis in non-ICU patients with infections \\ Viral infections}

Two double blind randomized placebo-controlled trials in 45 volunteers inoculated with either rhinovirus type 21 (study one) or rhinovirus type 25 (study two) demonstrated that administration of aspirin did not alter the proportion of patients who developed clinical illness or significantly alter the frequency or severity of symptoms [21]. Although the administration of aspirin significantly increased the shedding of rhinovirus in these trials, only one of the 45 patients developed fever so this increase in shedding was probably not attributable to the antipyretic effect of aspirin [21]. A similar study of 60 volunteers inoculated with rhinovirus and randomized to aspirin, paracetamol, ibuprofen, or placebo showed that the use of either aspirin or paracetamol was associated with suppression of the serum antibody response and a rise in circulating monocytes [22]. There were no significant differences in viral shedding among the four groups. However, the subjects treated with aspirin or paracetamol had a significant increase in nasal symptoms and signs compared to the placebo group [22]. In rhinovirusinfected volunteers treated with pseudoephedrine, the addition of ibuprofen had no effect on symptoms or on viral shedding or viral titers [23]. Again, only two of the 58 subjects developed a fever. A randomized controlled trial of children aged six months to six years with presumed non-bacterial infection and a fever of $\geq 38{ }^{\circ} \mathrm{C}$ demonstrated that administration of paracetamol increased the children's activity but not their mood, comfort or appetite [24].

Overall, the data from clinical studies in non-ICU patients do not support the hypothesis that antipyresis has a clinically significant beneficial or detrimental impact on the course or severity of minor viral illnesses. Although antipyretic medicines may increase the duration of rhinovirus shedding and time until crusting of chicken pox lesions, these effects seems unlikely to be attributable to antipyresis and are of uncertain clinical importance.

\section{Bacterial infections}

There are no randomized controlled trial data examining strategies of fever management on patient-centered outcomes in non-ICU patients with bacterial infections. However, there are historical examples of dramatic responses to treatment with therapeutic hyperthermia in some infectious diseases. It has been known since the time of Hippocrates that progressive paralysis due to neurosyphilis sometimes resolves after an illness associated with high fever. This observation led Julius Wagner-Jauregg to propose, in 1887, that inoculation of malaria might be a justifiable therapy for patients with 'progressive paralysis'. His rationale was that one could substitute an untreatable condition for a treatable one malaria being treatable with quinine. In 1917, he tested his hypothesis in nine patients with paralysis due to syphilis by injecting them with blood from patients suffering from malaria. Three of the patients had 
Table 1 Summary of key observational studies of fever and fever management in ICU patients

\begin{tabular}{lll}
\hline & Design, setting, and participants & Key findings \\
\hline Laupland et al. 2008 [30] & Retrospective cohort study of patients admitted to & - Fever of $\geq 38.3^{\circ} \mathrm{C}$ developed during $44 \%$ of ICU admissions and \\
& four ICUs in Calgary between 2000 and 2006; & high fever $\geq 39.3^{\circ} \mathrm{C}$ during $8 \%$ of admissions \\
$n=24,204$ ICU admissions in 20,466 patients & - Fever was not associated with increased ICU mortality but high \\
& fever was associated with a significantly increased risk of death
\end{tabular}

\begin{abstract}
Young et al. 2011 [31] Inception cohort study in three tertiary ICUs in Australia and New Zealand over six weeks in 2010 identifying patients with fever $\geq 38^{\circ} \mathrm{C}$ and known or suspected infection; $n=565$

Selladurai et al. 2011 [32]

Retrospective cohort study of patients admitted to a single tertiary ICU in Australia with sepsis between December 2009 and August 2010; $n=106$
\end{abstract}

Inception cohort study of consecutive patients admitted to 25 ICUs in Japan and Korea for more than 48 hours over three months in 2009; $n=1,425$
Laupland et al. 2012 [34]

Young et al. 2012 [35]

Niven et al. 2012 [36]
Inception cohort study of patients admitted to French ICUs contributing to the Outcomerea database between April 2000 and November 2010; $n=10,962$

Retrospective cohort study of 636,051 patients in Australia, New Zealand and the UK admitted to the ICU between 2005 until 2009
- $9 \%$ of patients admitted to ICU had or developed a fever and known or suspected infection

- Paracetamol was administered to about $2 / 3$ of patients with fever and known or suspected infection on any given day

- $69 \%$ of septic patients received paracetamol at least once during their first seven days in ICU

- $88 \%$ of septic patients with a fever $>38^{\circ} \mathrm{C}$ received paracetamol during their first seven days in ICU

- Septic patients with a fever $>38^{\circ} \mathrm{C}$ were 6.8 times $(95 \% \mathrm{Cl}$ 1.9-24.7) more likely to receive paracetamol than septic patients who were not febrile

- NSAID use independently associated with increased 28-day mortality in patients with sepsis (adjusted OR 2.61; $95 \% \mathrm{Cl}$

1.11-6.11; $p=0.03$ ) but with a trend towards a decreased 28-day mortality in patients without sepsis (adjusted OR 0.22; $95 \% 0.03$ $1.74 ; p=0.15)$

- Paracetamol use independently associated with increased 28-day mortality in patients with sepsis (adjusted OR 2.05; $95 \%$ Cl 1.19-3.55; $p=0.01$ ) but with a trend towards a decreased 28day mortality in patients without sepsis (adjusted OR 0.58; $95 \%$ $0.06-5.26 ; p=0.63$ )

- $25.7 \%$ of patients had a fever of $\geq 38.3^{\circ} \mathrm{C}$ at ICU presentation - Fever was not associated with increased mortality but hypothermia was an independent predictor of death in medical patients

- Elevated body temperature in the first 24 hours in ICU was associated with an increased risk of mortality in patients without infections and a decreased risk of mortality in patients with infections

- The cumulative incidence of fever $\geq 38.3$ during ICU admission decreased from $50.1 \%$ to $25.5 \%$ over the 5.5 years of the study

$\mathrm{Cl}$ : confidence interval; ICU: intensive care unit; NSAIDs: non-steroidal anti-inflammatory drugs; OR: odds ratio

remission of their paralysis. This led to further experiments and clinical observations on more than a thousand patients with remission occurring in $30 \%$ of patients with neurosyphilis-related progressive paralysis 'treated' with fever induced by malaria compared to spontaneous remission rates of only $1 \%$. This work on fever therapy led to Julius Wagner-Jauregg being awarded the Nobel Prize in Physiology or Medicine in 1927 [25]. Subsequently, fever therapy was shown to be effective in treating gonorrhea. Inducing a hyperthermia of $41.7^{\circ} \mathrm{C}$ for six hours in the 'Kettering hypertherm chamber' led to cure in $81 \%$ of cases [26].

A number of observational studies have examined the association between body temperature and outcome in patients with various bacterial infections, including pneumonia [27], spontaneous bacterial peritonitis [28], and Gram-negative bacteremia [29]. These studies show that the absence of fever is a sign of poor prognosis in patients with bacterial infections. Overall, the design of these studies does not allow one to distinguish between the absence of fever as a marked of disease severity or impaired host resilience rather than the presence of fever as a protective response.

\section{Fever in ICU patients with infections Observational studies of fever and fever management in ICU patients}

The epidemiology of fever in ICU patients and the frequency and utility of antipyretic use in ICU patients has been evaluated in a number of observational studies. The most important of the studies are summarized in Table 1.

The incidence of fever attributable to infection in observational studies in various critical care settings 
varies from $8 \%$ to $37 \%$ [31], [34], [36]-[41]. These studies use a variety of definitions of fever and a range of methods to record temperature, making comparisons between studies difficult. In these studies, the presence of fever was associated with either an increased risk of death [30], [39]-[41] or no difference in mortality risk compared to a normal temperature [34]. Only two studies have evaluated the mortality risk of patients with sepsis separately from patients without sepsis [33], [35]. In the first study, fever was associated with an increased 28-day mortality risk in patients without sepsis but not in patients with sepsis [33] raising the possibility that the presence of infection might be an important determinant of the significance of the febrile response in ICU patients. Similarly, in a retrospective cohort study [35] $(n=636,051)$ using two independent, multicenter, geographically distinct and representative databases we found that peak temperatures above $39.0{ }^{\circ} \mathrm{C}$ in the first 24 hours after ICU admission were generally associated with a reduced risk of in-hospital mortality in patients with an admission diagnosis of infection. Conversely, higher peak temperatures were associated with an increased risk of in-hospital mortality in patients with a non-infection diagnosis.

Overall, although one recent study suggests that the incidence of fever is decreasing over time [36], existing observational data suggest that fever is a commonly encountered abnormal physical sign in ICU patients. Unfortunately, because of the potential for unmeasured confounding factors, it is impossible to establish whether treating fever in ICU patients with an infection is beneficial or harmful on the basis of observational studies.

\section{Interventional studies of fever management in ICU patients}

Two recently published meta-analyses found no evidence that antipyretic therapy was either beneficial or harmful in non-neurologically injured ICU patients [2], [3]. Nearly all of the patients included in these meta-analyses had known or suspected sepsis and one of the metaanalyses only included patients with infection [3]. In both meta-analyses, the authors noted that existing studies lacked adequate statistical power to detect clinically important differences and recommended that large randomized controlled trials were urgently needed. The details of published interventional studies of fever management strategies in ICU patients are summarized in Table 2.

The largest published randomized controlled trial evaluated the use of ibuprofen in critically ill patients with sepsis [43]. Patients with severe sepsis were randomized to receive $10 \mathrm{mg} / \mathrm{kg}$ of ibuprofen or placebo every six hours for a total of eight doses. Although the use of ibuprofen significantly reduced body temperature, it did not alter 30-day mortality, which was $37 \%$ in the ibuprofen-treated group and $40 \%$ in the placebo group. This study was designed to evaluate the use of ibuprofen as an anti-inflammatory rather than as an anti-pyretic and, while the use of ibuprofen significantly reduced temperature compared to placebo, the study included patients who were hypothermic as well as patients who were febrile. An additional confounding factor was that patients assigned to the ibuprofen group were treated with paracetamol more often than those assigned to the control group. On the basis of this [43] and other smaller studies [45], [46] of non-steroidal anti-inflammatory drugs (NSAIDs) in critically ill patients, it is clear that NSAIDs are effective at reducing temperature in febrile ICU patients. However, there is no consistent mortality signal from the existing studies of NSAIDs. Some studies show trends towards benefit [42]-[44] with the use of NSAIDs and others show trends towards harm [45], [46].

The second largest published study of temperature management in febrile ICU patients evaluated the use of external cooling [49]. This study randomized 200 febrile patients with septic shock requiring vasopressors, mechanical ventilation, and sedation to external cooling to normothermia $\left(36.5-37^{\circ} \mathrm{C}\right)$ for 48 hours or no external cooling. The primary endpoint was the proportion of patients with a $50 \%$ decrease in vasopressor use at 48 hours after randomization. There was no significant difference between the treatment groups for the primary endpoint, which was achieved in $72 \%$ of the patients assigned to external cooling and $61 \%$ of the patients assigned to standard care. This study had a large number of secondary endpoints including mean body temperature, the proportion of patients who achieved $50 \%$ reduction in vasopressors at 2 hours, 12 hours, 24 hours, and 36 hours as well as day-14, ICU, and hospital mortality. The secondary endpoints generally favored external cooling and day-14 mortality was noted to be significantly lower in the external cooling group (19\% vs. $34 \% ; \mathrm{p}=0.0013)$. This difference in mortality was not evident by the time of ICU or hospital discharge and caution should be exerted in interpreting these endpoints as it is possible that they were affected by a type 1 error due to a lack of statistical power.

Another trial compared temperature control strategies in a tertiary trauma ICU and randomized patients to either aggressive temperature control or a permissive strategy [47]. Patients assigned to the aggressive treatment arm received regular paracetamol once the temperature exceeded $38.5^{\circ} \mathrm{C}$ and physical cooling was added when the temperature exceeded $39.5^{\circ} \mathrm{C}$. Patients assigned to the permissive treatment arm received paracetamol and cooling when the temperature reached $40{ }^{\circ} \mathrm{C}$. This trial originally aimed to enroll 672 patients; however, it was stopped by the Data Safety Monitoring Board after enrolment of 82 patients due to a trend 
Table 2 Summary of randomized controlled trials investigating the management of fever in critically ill adults

\begin{tabular}{|c|c|c|}
\hline & Design, setting, and participants & Key findings \\
\hline Bernard et al. 1991 [42] & $\begin{array}{l}\text { Double blind placebo-controlled trial of ibuprofen in } \\
\text { patients with severe sepsis; } n=30\end{array}$ & $\begin{array}{l}\text { - Ibuprofen significantly reduced temperature, heart rate, and } \\
\text { peak airway pressure } \\
\text { - There was no significant difference between ibuprofen and } \\
\text { placebo in terms of in-hospital mortality rate ( } 18.8 \% \text { ibuprofen- } \\
\text { treated group vs. } 42.9 \% \text { placebo-treated group) }\end{array}$ \\
\hline
\end{tabular}

Bernard et al. 1997 [43] Double blind placebo-controlled trial of ibuprofen in patients with severe sepsis in seven centers in North America; $n=455$

Memis et al. 2004 [44]

Morris et al. 2011 [45]

Haupt et al. 1991 [46]

Schulman et al. 2006 [47]

Niven et al. 2012 [48]

Schortgen et al. 2012 [49]
Double blind placebo-controlled trial of lornoxicam in patients with severe sepsis in one center in Turkey; $n=40$

Multicenter, randomized trial comparing the antipyretic efficacy of a single dose of placebo, $100 \mathrm{mg}, 200 \mathrm{mg}$, or $400 \mathrm{mg}$ of i. v. ibuprofen in hospitalized patients of whom $>90 \%$ had infections; $n=120$ (53 critically ill)

Multicenter, placebo-controlled randomized trial of ibuprofen in patients with severe sepsis; $n=29$

Single center, unblinded, randomized trial of aggressive vs. permissive temperature management in febrile patients in a trauma ICU; $n=82$

Multicenter, unblinded randomized trial of aggressive vs. permissive temperature management in febrile ICU patients; $n=26$

Multicenter, randomized controlled trial of external cooling in patients with fever and septic shock receiving mechanical ventilation in seven centers in France; $n=200$
- Ibuprofen significantly reduced temperature, heart rate, oxygen consumption, and lactic acidosis in patients with severe sepsis - Ibuprofen did not alter the incidence or duration of shock or ARDS and had no significant effect on 30-day mortality (37\% ibuprofen-treated group vs. $40 \%$ placebo-treated group)

- No significant difference between lornoxicam and placebo was demonstrated in terms of hemodynamic parameters, biochemical parameters, cytokine levels, or ICU mortality (35\% lornoxicam-treated group vs. $40 \%$ placebo-treated group)

- All doses of ibuprofen tested were effective in lowering temperature

- There were no significant difference between treatment groups with respect to ventilation requirements, length of stay or in-hospital mortality (4\% placebo, 3\% $100 \mathrm{mg}$ ibuprofen, 7\% $200 \mathrm{mg}$ ibuprofen, $6 \% 400 \mathrm{mg}$ ibuprofen)

- |buprofen significantly reduced body temperature - There was no significant difference between the treatment groups in terms of in-hospital mortality $30.8 \%$ in the placebo group vs. $56.3 \%$ in the ibuprofen group)

- There was no significant difference between the treatment arms in terms of the number of new infections

- The in-hospital mortality was $15.9 \%$ in the aggressive treatment group and $2.6 \%$ in the permissive treatment group $(p=0.06)$

- The mean daily temperature was lower in the patients assigned to aggressive fever management

- The in-hospital mortality was $21 \%$ in the aggressive treatment group and $17 \%$ in the permissive treatment group $(p=1.0)$

- External cooling significantly reduced body temperature - External cooling did not alter the proportion of patients who had a $50 \%$ reduction in vasopressor dose after 48 hours - Day-14 mortality was significantly lower in the patients assigned to external cooling but there was no significant difference between the groups in terms of ICU or in-hospital mortality

ARDS: acute respiratory distress syndrome; ICU: intensive care unit.

towards increased mortality in the aggressive treatment group. While all deaths were attributed to septic causes, conventional stopping rules were not used and differences between the study treatment arms could be due to chance. This study had other major limitations including a lack of blinding or placebo-control, and potential confounding from the uncontrolled use of other antipyretic drugs and per-protocol use of external cooling. A similar open-label randomized study enrolled 26 febrile ICU patients and assigned them to aggressive or permissive temperature management [48]. In this study, the aggressive fever control group received paracetamol $650 \mathrm{mg}$ enterally every 6 hours when the temperature was $\geq 38.3^{\circ} \mathrm{C}$ and received physical cooling for temperature $\geq 39.5^{\circ} \mathrm{C}$. The permissive group did not receive paracetamol until the temperature was $\geq 40{ }^{\circ} \mathrm{C}$ and did not receive physical cooling until the temperature reached $\geq 40.5{ }^{\circ} \mathrm{C}$. All patients assigned to aggressive temperature management had an infectious etiology of fever and $75 \%$ of patients assigned to the permissive management arm had an infectious etiology at baseline. The 28-day all cause mortality was not significantly different between the two groups.

The safety and efficacy of using paracetamol to treat fever in ICU patients with infections is being evaluated in a 700-patient phase IIb, multicenter, randomized placebo-controlled trial (the HEAT trial), which is due to complete enrolment in November 2014 [50]. 


\section{Conclusion}

There is a significant body of animal data demonstrating that fever is an important component of the host response to infection and confers a survival advantage in a number of animal species. The conservation of a metabolically costly response across a broad range of animal species suggests that the response probably has an evolutionary advantage. There are some interesting historical examples of hyperthermia being employed to treat infectious diseases. However, in the modern era the relevance of these examples is questionable. Furthermore, arguments based on the evolutionary importance of the febrile response do not necessarily apply to critically ill patients who are, by definition, supported beyond the limits of normal physiological homeostasis. Humans are not adapted to critical illness. In the absence of modern medicine and intensive care, most critically ill patients with fever and infection would presumably die. Among critically ill patients, it is biologically plausible that there is a balance to be struck between the potential benefits of reducing metabolic rate that come with fever control and the potential risks of a deleterious effect on host defense mechanisms. Remarkably, at present, we do not know what effect treating fever in critically ill patients with infections has on patient-centered outcomes. These treatments include commonly used interventions such as paracetamol and physical cooling. This area of research is of high priority given the global epidemiology of fever in critically ill patients and the generalizability of the candidate interventions.

\section{List of abbreviations used}

AP-1: activator protein-1; ARDS: acute respiratory distress syndrome; $\mathrm{Cl}$ : confidence interval; COX-2: cyclo-oxygenase; HSPs: heat shock proteins; ICU: intensive care unit; IL: interleukin; IL-1RA: IL-1 receptor agonist; LPS: lipopolusaccharide; NF-kB: nuclear factor-kappa B; NSAIDs: non-steroidal anti-inflammatory drugs; OR: odds ratio; OVLT: organum vasculosum of the laminae terminalis; $\mathrm{PGE}_{2}$ : prostaglandin $\mathrm{E}_{2}$; TLR-4: Toll-like receptor 4; TNF: tumor necrosis factor.

\section{Competing interests}

The authors declare that they have no competing interests.

\section{Declarations}

Funding for publication of this article comes from Public Hospital Funds that are allocated for Training, Education and Study Leave purposes.

\section{Author details}

'Intensive Care Unit, Wellington Regional Hospital, Wellington, New Zealand. ${ }^{2}$ Department of Intensive Care Medicine, St. George Hospital, Kogarah, Australia

\section{Published: 18 March 2014}

\section{References}

1. Osler W: The study of the fevers of the south. JAMA 1986, XXVI:1001-1004.

2. Niven DJ, Stelfox HT, Laupland KB: Antipyretic therapy in febrile critically ill adults: A systematic review and meta-analysis. J Crit Care 2013, 28:303-310.

3. Jefferies S, Weatherall M, Young P, Eyers S, Perrin KG, Beasley CR: The effect of antipyretic medications on mortality in critically ill patients with infection: a systematic review and meta-analysis. Crit Care Resus 2011, 13:125-131.

4. Horvath SM, Spurr GB, Hutt BK, Hamilton LH: Metabolic cost of shivering J Appl Physiol 1956, 8:595-602.
5. Manthous CA, Hall JB, Olson D, Singh M, Chatila W, Pohlman A, Kushner R, Schmidt GA, Wood LD: Effect of cooling on oxygen consumption in febrile critically ill patients. Am J Respir Crit Care Med 1995, 151:10-14.

6. Chu CM, Tian SF, Ren GF, Zhang YM, Zhang LX, Liu GQ: Occurrence of temperature-sensitive influenza A viruses in nature. J Virol 1982, 41:353-359.

7. Small PM, Tauber MG, Hackbarth CJ, Sande MA: Influence of body temperature on bacterial growth rates in experimental pneumococcal meningitis in rabbits. Infect Immun 1986, 52:484-487.

8. Enders JF, Wu CJ, Shaffer MF: Studies on natural immunity to pneumococcus type III: IV. Observations on a non-type specific humoral factor involved in resistance to pneumococcus type III. J Exp Med 1936 64:425-438.

9. Moench M: A study of the heat sensitivity of the meningococcus in vitro within the range of therapeutic temperatures. J Lab Clin Med 1926, 57:665-676

10. Khanna MR, Bhavsar SP, Kapadnis BP: Effect of temperature on growth and chemotactic behaviour of Campylobacter jejuni. Lett App/ Microbio/ 2006 43:84-90.

11. Bernheim HA, Kluger MJ: Fever: effect of drug-induced antipyresis on survival. Science 1976, 193:237-239.

12. Reynolds WW: Fever and antipyresis in the bluegill sunfish, Lepomis macrochirus. Comparative biochemistry and physiology. Comp Biochem Physiol C 1977, 57:165-167.

13. Kluger M: The evolution of fever. In Fever: Its Biology, Evolution, and Function, 1st edn.Edited by Kluger M Princeton University Press, New Jersey, 1979: 106-127.

14. Strouse S: Experimental Studies on Pneumococcus Infections. J Exp Med 1909, 11:743-761.

15. Armstrong C: Some recent research in the field of neurotropic viruses with especial reference to lymphocytic choriomeningitis and herpes simplex. Mil Surg 1942, 91:129-145.

16. Eyers S, Weatherall M, Shirtcliffe P, Perrin K, Beasley R: The effect on mortality of antipyretics in the treatment of influenza infection: systematic review and meta-analysis. J R Soc Med 2010, 103:403-411.

17. Kluger MJ, Vaughn LK: Fever and survival in rabbits infected with Pasteurella multocida. J Physio/ 1978, 282:243-251.

18. Akins C, Thiessen D, Cocke R: Lipopolysaccharide increases ambient temperature preference in C57BL/6J adult mice. Physiol Behav 1991 50:461-463.

19. Jiang Q, Cross AS, Singh IS, Chen TT, Viscardi RM, Hasday JD: Febrile core temperature is essential for optimal host defense in bacterial peritonitis. Infect Immun 2000, 68:1265-1270.

20. Jefferies S, Weatherall M, Young P, Eyers S, Beasley R: Systematic review and meta-analysis of the effects of antipyretic medications on mortality in Streptococcus pneumoniae infections. Postgrad Med J 2012, 88:21-27.

21. Stanley ED, Jackson GG, Panusarn C, Rubenis M, Dirda V: Increased virus shedding with aspirin treatment of rhinovirus infection. JAMA 1975, 231:1248-1251.

22. Graham NM, Burrell CJ, Douglas RM, Debelle P, Davies L: Adverse effects of aspirin, acetaminophen, and ibuprofen on immune function, viral shedding, and clinical status in rhinovirus-infected volunteers. J Infect Dis 1990, 162:1277-1282

23. Sperber SJ, Sorrentino JV, Riker DK, Hayden FG: Evaluation of an alpha agonist alone and in combination with a nonsteroidal antiinflammatory agent in the treatment of experimental rhinovirus colds. Bull N Y Acad Med 1989, 65:145-160.

24. Kramer MS, Naimark LE, Roberts-Brauer R, McDougall A, Leduc DG : Risks and benefits of paracetamol antipyresis in young children with fever of presumed viral origin. Lancet 1991, 337:591-594.

25. Wagner-Jauregg J: The treatment of dementia paralytica by malaria innoculation. In Nobel Lectures: Physiology or Medicine 1922-1941. Elsevier, New York, 1927: 159-169

26. Owens C: The value of fever therapy for gonorrhea. JAMA 1936, 107:1942-1946.

27. Ahkee S, Srinath L, Ramirez J: Community-acquired pneumonia in the elderly: association of mortality with lack of fever and leukocytosis. South Med J 1997, 90:296-298.

28. Weinstein MP, Iannini PB, Stratton CW, Eickhoff TC: Spontaneous bacterial peritonitis. A review of 28 cases with emphasis on improved survival and factors influencing prognosis. Am J Med 1978, 64:592-598. 
29. Bryant RE, Hood AF, Hood CE, Koenig MG: Factors affecting mortality of gram-negative rod bacteremia. Arch Intern Med 1971, 127:120-128.

30. Laupland KB, Shahpori R, Kirkpatrick AW, Ross T, Gregson DB, Stelfox HT: Occurrence and outcome of fever in critically ill adults. Crit Care Med 2008 36:1531-1535.

31. Young P, Saxena M, Eastwood GM, Bellomo R, Beasley R: Fever and fever management among intensive care patients with known or suspected infection: a multicentre prospective cohort study. Crit Care Med 2011, 13:97-102.

32. Selladurai S, Eastwood GM, Bailey M, Bellomo R: Paracetamol therapy for septic critically ill patients: a retrospective observational study. Crit Care Resus 2011, 13:181-186.

33. Lee BH, Inui D, Suh GY, Kim JY, Kwon JY, Park J, Tada K, Tanaka K, letsegu K, Uehara K, Dote K, Tajimi K, Morita K, Matsuo K, Hoshino K, Hosokawa K, Lee KH, Lee KM, Takatori M, Nishimura M, Sanui M, Ito M, Egi M, Honda N, Okayama N, Shime N, Tsuruta R, Nogami S, Yoon SH, Fujitani S, Koh SO, Takeda S, Saito S, Hong SJ, Yamamoto T, Yokoyama T, Yamaguchi T, Nishiyama T, Igrashi T, Kakihana Y, Koh Y, Fever and Antipyretic in Critically il patients Evaluation (FACE) Study Group: Association of body temperature and antipyretic treatments with mortality of critically ill patients with and without sepsis: multi-centered prospective observational study. Crit Care 2012, 16:R33.

34. Laupland KB, Zahar JR, Adrie C, Schwebel C, Goldgran-Toledano D, Azoulay E, Garrouste-Orgeas M, Cohen Y, Jamali S, Souweine B, Darmon M, Timsit JF: Determinants of temperature abnormalities and influence on outcome of critical illness. Crit Care Med 2012, 40:145-151.

35. Young PJ, Saxena M, Beasley R, Bellomo R, Bailey M, Pilcher D, Finfer S, Harrison D, Myburgh J, Rowan K: Early peak temperature and mortality in critically ill patients with or without infection. Intensive Care Med 2012 38:437-444.

36. Niven DJ, Stelfox HT, Shahpori R, Laupland KB: Fever in adult ICUs: An interrupted time series analysis. Crit Care Med 2013, 41:1863-1869

37. Kiekkas P, Velissaris D, Karanikolas M, Aretha D, Samios A, Skartsani C, Baltopoulos Gl, Filos KS: Peak body temperature predicts mortality in critically ill patients without cerebral damage. Heart Lung 2010, 39:208-216.

38. Moran JL, Peter JV, Solomon PJ, Grearly B, Smith T, Ashforth W, Wake M, Peake SL, Peisach AR: Tympanic temperature measurements: are they reliable in the critically ill? A clinical study of measures of agreement. Crit Care Med 2007, 35:155-164.

39. Circiumaru B, Baldock $G$, Cohen J: A prospective study of fever in the intensive care unit. Intensive Care Med 1999, 25:668-673.

40. Peres Bota D, Lopes Ferreira F, Melot C, Vincent JL: Body temperature alterations in the critically ill. Intensive Care Med 2004, 30:811-816.
41. Barie PS, Hydo LJ, Eachempati SR: Causes and consequences of fever complicating critical surgical illness. Surg Infect (Larchmt) 2004, 5:145-159.

42. Bernard GR, Reines HD, Halushka PV, Higgins SB, Metz CA, Swindell BB, Wright $P E$, Watts FL, Vrbanac JJ: Prostacyclin and thromboxane A2 formation is increased in human sepsis syndrome. Effects of cyclooxygenase inhibition. Am Rev Respir Dis 1991, 144:1095-1101.

43. Bernard GR, Wheeler AP, Russell JA, Schein R, Summer WR, Steinberg KP, Fulkerson WJ, Wright PE, Christman BW, Dupont WD, Higgins SB, Swindell BB: The effects of ibuprofen on the physiology and survival of patients with sepsis. The Ibuprofen in Sepsis Study Group. N Engl J Med 1997, 336:912-918.

44. Memis D, Karamanlioglu B, Turan A, Koyuncu O, Pamukcu Z: Effects of lornoxicam on the physiology of severe sepsis. Crit Care 2004, 8:R474-R482.

45. Morris PE, Promes JT, Guntupalli KK, Wright PE, Arons MM: A multi-center, randomized, double-blind, parallel, placebo-controlled trial to evaluate the efficacy, safety, and pharmacokinetics of intravenous ibuprofen for the treatment of fever in critically ill and non-critically ill adults. Crit Care 2010, 14:R125.

46. Haupt MT, Jastremski MS, Clemmer TP, Metz CA, Goris GB: Effect of ibuprofen in patients with severe sepsis: a randomized, double-blind, multicenter study. The Ibuprofen Study Group. Crit Care Med 1991, 19:1339-1347.

47. Schulman Cl, Namias N, Doherty J, Manning RJ, Li P, Elhaddad A, Lasko D, Amortequi J, Dy CJ, Dlugasch L, Baracco G, Cohn SM: The effect of antipyretic therapy upon outcomes in critically ill patients: a randomized, prospective study. Surg Infect (Larchmt) 2005, 6:369-375.

48. Niven DJ, Stelfox HT, Leger C, Kubes P, Laupland KB: Assessment of the safety and feasibility of administering antipyretic therapy in critically ill adults: A pilot randomized clinical trial. J Crit Care 2013, 28:296-302.

49. Schortgen F, Clabault K, Katsahian S, Devaquet J, Mercat A, Deye N, Dellamonica J, Bouadma L, Cook F, Beji O, Brun-Buisson C, Lemaire F: Fever control using external cooling in septic shock: a randomized controlled trial. Am J Respir Crit Care Med 2012, 185:1088-1095.

50. Young PJ, Saxena MK, Bellomo R, Freebairn RC, Hammond NE, van Haren FM Henderson SJ, McArthur CJ, McGuiness SP, Mackle D, Myburgh JA, Weatheral M, Webb SA, Beasley RW, ANZICS Clinical Trials Group: The HEAT trial: a protocol for a multicentre randomised placebo-controlled trial of IV paracetamol in ICU patients with fever and infection. Crit Care Resus 2012, 14:290-296.

doi:10.1186/cc13773

Cite this article as: Young PJ, Saxena M: Fever management in intensive care patients with infections. Critical Care 2014, 18:206. 